\begin{tabular}{|l|l|l||}
\hline \multicolumn{2}{|c|}{ PublisherInfo } \\
\hline \hline PublisherName & $:$ & BioMed Central \\
\hline \hline PublisherLocation & $:$ & London \\
\hline \hline PublisherImprintName & $:$ & BioMed Central \\
\hline \hline
\end{tabular}

\title{
Exercise testing to predict mortality
}

\begin{tabular}{|l|l|l||}
\hline \multicolumn{2}{|c|}{ ArticleInfo } \\
\hline \hline ArticleID & $:$ & 4165 \\
\hline \hline ArticleDOI & $:$ & $10.1186 /$ ccf-1999-2241 \\
\hline \hline ArticleCitationID & $:$ & 2241 \\
\hline \hline ArticleSequenceNumber & $:$ & 24 \\
\hline \hline ArticleCategory & $:$ & Paper Report \\
\hline \hline ArticleFirstPage & $:$ & 1 \\
\hline \hline ArticleLastPage & $:$ & 4 \\
\hline \hline & & RegistrationDate : 1999-11-11 \\
ArticleHistory & $:$ & OnlineDate $\quad$ 1999-11-11 \\
\hline \hline ArticleCopyright & $:$ & Current Science Ltd1999 \\
\hline \hline ArticleGrants & $:$ & \\
\hline \hline ArticleContext & $:$ & 1305422 \\
\hline \hline
\end{tabular}




\section{Keywords}

Exercise, mortality, risk factor, thallium scan, vagus

\section{Comments}

Risk factors which identify high risk groups often only predict small numbers of deaths, and the search continues for a simple tool which can predict mortality. In this large study, patients whose heartrates failed to recover quickly after standard exercise testing had a worse overall mortality, although the numbers showing this response were relatively small (26\% in the population studied). Exercise testing is non-invasive and relatively easy to perform and so would be ideal for identifying the high risk surgical patient who requires intensive care in the perioperative period. However this population was not targeted in this paper and further work is needed to examine whether an abnormal heart rate recovery could identify this group. Although a mechanism to explain these findings is not forthcoming, it is believable that a severe oxygen debt following exercise may influence vagal reactivation and that abnormal heart rate recovery is a non-invasive marker of this.

\section{Introduction}

Several studies have addressed the prognostic value of changes in heart rate occurring during maximum treadmill stress testing. However, little is known about the relationship between the initial rate of decrease in heart rate following exercise, and mortality. The decrease in heart rate after exercise is a consequence of reactivation of vagal activity (which is inhibited during exercise), and previous work has shown that high vagal activity reduces the risk of death. Consequently the initial rate of decrease in heart rate following exercise may predict outcome.

\section{Aims}

To determine the use of heart-rate recovery following exercise as a predictor of mortality. 


\section{Methods}

In total, 2428 consecutive patients referred for exercise-testing and thallium scintigraphy over a 3 year period (1990-1993) were followed up for 6 years. Exclusions included heart failure and other appropriate pathologies that are known to have an effect on vagal activity. Baseline clinical information was recorded for subsequent multivariable regression analysis. Heart-rate recovery was defined as the reduction in rate following cessation of peak exercise, to one minute later. An abnormal recovery was defined as a reduction of 12 beats per minute or less over this period (see paper for explanation).

\section{Results}

An abnormal heart-rate recovery was found in $26 \%$ of patients, and baseline characteristics also showed that this group were older and more likely to have hypertension, diabetes and Q waves on their electrocardiogram. This group was also more likely to have perfusion defects on thallium scintigraphy, but there was no difference in angina or ST-segment changes during exercise testing. The 6 year followup period resulted in $213(9 \%)$ deaths from all causes and of these, $120(56 \%)$ had an abnormal heartrate recovery. Mortality at 6 years was $19 \%$ for patients with an abnormal heart rate recovery compared to $5 \%$ with a normal recovery (sensitivity $56 \%$, specificity $77 \%$, positive predictive value $19 \%$ and negative predictive value 95\%). The best predictor of death was an abnormal heart-rate recovery using multivariable regression analysis. There was a strong association between abnormal heart-rate recovery and a reduction in exercise capacity.

\section{Discussion}

The failure of heart rate to decline quickly after exercise appears to be associated with an increase in overall mortality. Consequently this may be a relatively simple and non-invasive means of identifying high risk groups. An explanation for this association is not clear but the results appear to support previous work which has shown that high vagal activity reduces the risk of death. The authors comment that other measurements not available in this study (improved thallium scans, measurements of left ventricular function) may also be important predictors of mortality. 


\section{References}

1. Cole CR, Blackstone EH, Pashkow FJ, Snader CE, Lauer MS: Heart-rate recovery immediately after exercise as a predictor of mortality. N Engl J Med. 1999, 18: 1351-1357.

This PDF file was created after publication. 